\title{
Developing breast cancer guidelines: keep cherishing our former knowledge as we continue to acquire new
}

\author{
Mitsuhiro Hayashi \\ Department of Breast Surgery, Women's Center, Yotsuya Medical Cube, Tokyo, Japan \\ Correspondence to: Mitsuhiro Hayashi, MD, PhD. Department of Breast Surgery, Women's Center, Yotsuya Medical Cube, 7-7 Nibancho, Chiyoda- \\ ku, Tokyo, 102-0084, Japan. Email: mitsuhayashi-ncd@umin.ac.jp. \\ Comment on: Jiang Z, Song E, Wang X, et al. Guidelines of Chinese Society of Clinical Oncology (CSCO) on Diagnosis and Treatment of Breast \\ Cancer (2020 version). Transl Breast Cancer Res 2020. doi: 10.21037/tbcr-2020-2.
}

Received: 26 October 2020; Accepted: 31 October 2020; Published: 31 October 2020.

doi: $10.21037 /$ tbcr-20-56

View this article at: http://dx.doi.org/10.21037/tbcr-20-56

It is not easy to assemble the necessary information and evaluate the pros and cons of day-to-day clinical practice $(1,2)$. Clinical practice guidelines are systematically developed documents that summarize the best evidence available. They are derived from multiple treatments and diagnostic examinations and provide a series of recommendations based on a balance of advantages and disadvantages to help clinicians decide appropriate medical care in specific clinical situations. Guidelines assist in the effective and efficient implementation of the latest and best medical procedures at the time. Clinical guidelines help in the practice of evidence-based medicine. It is an essential tool for sharing information, not only to the physician but also to the entire health care team. Clinical guidelines also allow patients and their families to make reliably informed decisions.

Breast cancer practice guidelines have been widely released in Europe, the United States, and, more recently, in Asia (3-5). The first step is to address the critical issues in breast cancer care and establish clinical questions. Next, a systematic review is conducted to discuss the evidence's certainty, the balance of benefits and harms, and finally, develop recommendations. With this contribution in mind, I deeply respect the tremendous efforts of those involved in developing practice guidelines.

What should we know about the guidelines? Clinical guidelines do not apply to every patient. Clinical guidelines are not mandatory for all patients to adhere at all times. In other words, the recommendations given in the guidelines are not the only correct answers. It is solely a matter of balancing benefit and harm in the patient population. Guidelines recommend examinations and treatment procedures that are considered to have the most significant benefit to the patient at the time. Since medicine is always an area of uncertainty, some patients may experience more harm as a result. It is important to use clinical guidelines adequately by selecting the medical treatment that will most likely provide a benefit based on the patient's physical and mental health and preferences. A good guideline does not list evidence from clinical trials and other studies but rather provides actionable recommendations and options closely aligned with the healthcare system and available resources in medical areas, regions, or nations. It is not unexpected that the strengths of the recommendations and the guideline's presentation would vary internationally.

The authors of the Guidelines of CSCO on Diagnosis and Treatment of Breast Cancer have developed level-bylevel recommendations based on the best evidence available and regional health care systems for the broad areas of diagnosis and treatment of early to recurrent/metastatic breast cancer and the relief from adverse events of specific treatments (6). These guidelines are expected to improve the quality of life and lower mortality rates of breast cancer patients.

What should we do next, given the guidelines? The ultimate goal of a clinical guideline is to improve the quality of medical care and outcomes. Regarding this, it is necessary to adhere to the guidelines and accumulate 
reliable quality medical information. This process will expose certain issues that are not covered by the current guidelines. The guidelines should be regularly updated based on user feedback and the latest medical information updated anytime and anywhere. Early-career physicians and team staff must closely read and practice these guidelines. They will be expected to reach out to regional professional experts and opinion leaders in Asia, Europe, and the United States for the clinical questions from that experience. Experts occasionally choose not to follow guidelines and go beyond the recommendations because they know the background behind the clinical trials that frequently affects the development of guidelines. Brainstorming new clinical questions raised by young physicians and real practices by experts beyond the guidelines will provide a stepping stone for novel evidence development. The establishment of such a sustainable ecosystem will contribute to improved quality and ideal healthcare.

With the initiation of cancer genomic medicine, the diversity of cancers has been revealed, and the characteristics and position of Asian breast cancer have been discussed. In parallel, work to create clinical questions and establish evidence in Asia has already begun. For instance, Asian-led multicenter international clinical trials, such as the PEONY (7) and PATHWAY (8) trials, are good demonstrations of this. The historical accumulation of real-world data that conforms to clinical guidelines and the learning of this practice information can be expected to create new and innovative medicine combined with emerging scientific technologies, such as next-generation omics and artificial intelligence.

\section{Acknowledgments}

I am grateful to all the people involved in this work, including the staff at Yotsuya Medical Cube, Y. H., M. H., and H. H., for their tremendous support.

Funding: None.

\section{Footnote}

Provenance and Peer Review: This article was commissioned by the editorial office, Translational Breast Cancer Research. The article did not undergo external peer review.

Conflicts of Interest: The author has completed the ICMJE uniform disclosure form (available at http://dx.doi. org/10.21037/tbcr-20-56). The author has no conflicts of interest to declare.

Ethical Statement: The author is accountable for all aspects of the work in ensuring that questions related to the accuracy or integrity of any part of the work are appropriately investigated and resolved.

Open Access Statement: This is an Open Access article distributed in accordance with the Creative Commons Attribution-NonCommercial-NoDerivs 4.0 International License (CC BY-NC-ND 4.0), which permits the noncommercial replication and distribution of the article with the strict proviso that no changes or edits are made and the original work is properly cited (including links to both the formal publication through the relevant DOI and the license). See: https://creativecommons.org/licenses/by-nc-nd/4.0/.

\section{References}

1. Eddy DM. Clinical decision making: from theory to practice. Designing a practice policy. Standards, guidelines, and options. JAMA 1990;263:3077, 3081, 3084.

2. Putora PM. Decision making in oncology. JCO Clin Cancer Inform 2019;3:1-2.

3. Iwata H, Saji S, Ikeda M, et al. The Japanese Breast Cancer Society Clinical Practice Guidelines, 2018 edition: the tool for shared decision making between doctor and patient. Breast Cancer 2020;27:1-3.

4. Park YH, Senkus-Konefka E, Im SA, et al. Pan-Asian adapted ESMO Clinical Practice Guidelines for the management of patients with early breast cancer: a KSMO-ESMO initiative endorsed by CSCO, ISMPO, JSMO, MOS, SSO and TOS. Ann Oncol 2020;31:451-69.

5. National Comprehensive Cancer Network. NCCN Clinical Practice Guidelines in Oncology. 2020. Available online: https://www.nccn.org/professionals/physician_gls/ default.aspx

6. Jiang Z, Song E, Wang X, et al. Guidelines of Chinese Society of Clinical Oncology (CSCO) on Diagnosis and Treatment of Breast Cancer (2020 version). Transl Breast Cancer Res 2020. doi: 10.21037/tbcr-2020-2.

7. Shao Z, Pang D, Yang H, et al. Efficacy, safety, and tolerability of pertuzumab, trastuzumab, and docetaxel for patients with early or locally advanced ERBB2-positive breast cancer in Asia: the PEONY phase 3 randomized clinical trial. JAMA Oncol 2020;6:e193692. 
8. Noguchi E, Hata T, Nakamura K, et al. Abstract OT302-02: PATHWAY: Asian, multicenter, phase 3 trial of tamoxifen with or without palbociclib \pm goserelin in

doi: $10.21037 /$ tbcr-20-56

Cite this article as: Hayashi M. Developing breast cancer guidelines: keep cherishing our former knowledge as we continue to acquire new. Transl Breast Cancer Res 2020;1:23. women with hormone receptor-positive, HER2-negative advanced or metastatic breast cancer. Cancer Res 2019. doi: 10.1158/1538-7445.SABCS18-OT3-02-02. 